\title{
Atrial Fibrillation Following Electrical Injury
}

\author{
Gurpreet S. WAnder, M.D., D.M., Rajinder K. Bansal, M.D.,* \\ Inder S. Anand, F.R.C.P., D.Phil. (Oxon.), F.A.C.C., \\ S. Arora, M.D., Shashi B. Khurana, M.D., \\ and Livtar S. Chawla, M.D.
}

\begin{abstract}
SUMMARY
The development of atrial fibrillation in 2 patients, following an electrical shock is reported. One patient, with an underlying pre-excitation syndrome, had to be cardioverted due to rapid ventricular rate and hypotension. The other, with normal conduction, tolerated the arrhythmia well and atrial fibrillation reverted spontaneously after 24 hours.
\end{abstract}

\section{Key Words :}

Atrial fibrillation Electrical shock Pre-excitation

7 HE clinical spectrum of electrical injuries is complex. ${ }^{11}$ Accidental elec1 trical injury is known to cause skin burns, musculo-skeletal problems, myoglobinuria, renal insufficiency, cataracts and central nervous system, gastrointestinal and pulmonary complications. ${ }^{1-4)}$ A number of cardiovascular complications have also been described. ${ }^{11-4)}$ However, atrial fibrillation is seldom seen. In this paper we describe 2 cases where accidental electrical injury caused atrial fibrillation.

\section{CAse RePort}

$A B$, a 40 -year-old male, was admitted to the emergency services of our hospital in a state of shock. He had accidentally touched a live wirc (220 volts, $50 \mathrm{~Hz}$ ) in his house. Clinical examination revealed that the patient was in shock with unrecordable blood pressure. Electrocardiogram showed fast atrial fibrillation (Fig. 1) with a rate of $200 / \mathrm{min}$. He was successfully cardioverted with 25 joules. His blood pressure gradually improved, urine output increased and he regained consciousness. A repeat electrocardiogram

From the Departments of Medicine and Cardiology, Dayanand Medical College and Hospital Ludhiana and *Department of Cardiology, Postgraduate Institute of Medical Education and Research, Chandigarh, India.

Address for correspondence: G. S. Wander, M.D., Department of Cardiology, Dayanand Medical College and Hospital, Ludhiana, Punjab, India.

Received for publication February 28, 1991.

Accepted June 14, 1991. 


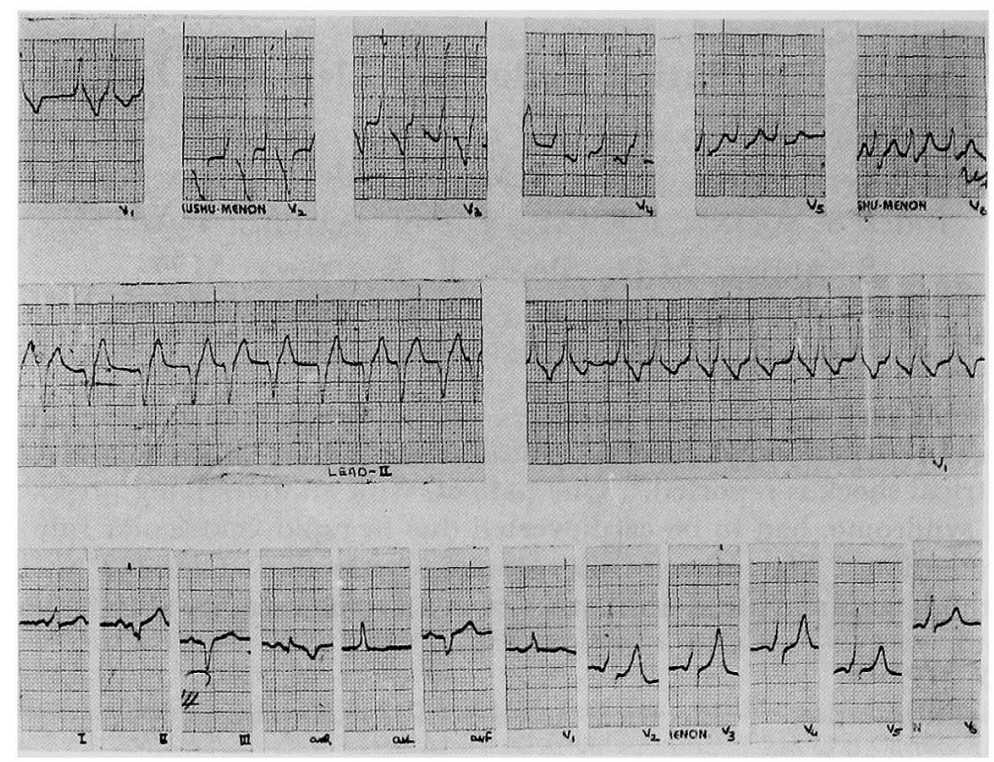

Fig. 1. Electrocardiogram of the first patient showing atrial fibrillation with ventricular rate of $200 / \mathrm{min}$. Upper trace shows atrial fibrillation in leads $V_{1}-V_{6}$. Middle trace: rhythm strip in leads II and $V_{1}$. Lower trace revealed the underlying pre-excitation syndrome after cardioversion.

(Fig. 1) showed an underlying pre-excitation with Type I WPW syndrome. Cardiovascular examination, chest $\mathrm{x}$ ray and clinical chemistry were normal. The CK-MB was normal. The patient had no previous history of atrial arrhythmia or any other manifestation of WPW syndrome.

$C D$, a 35-year-old male, received an electric shock while repairing a table fan. On examination he was drowsy and in atrial fibrillation with a rate of $110 / \mathrm{min}$. Blood pressure was $120 / 80 \mathrm{mmHg}$. There were no signs of electrical burns or other trauma. Physical examination was normal. Electrocardiogram showed atrial fibrillation (Fig. 2) but was otherwise normal. Since the patient was hemodynamically stable and heart rate was controlled, no active treatment was given. He was monitored in the intensive care unit. His drowsiness improved over the next few hours and the atrial fibrillation reverted spontaneously to sinus rhythm 24 hours later (Fig. 2). Chest $\mathrm{x}$ ray and echocardiogram done the next day were normal. Neither of these cases, on follow up for a period of 8-12 months, has had any recurrence of atrial fibrillation. 


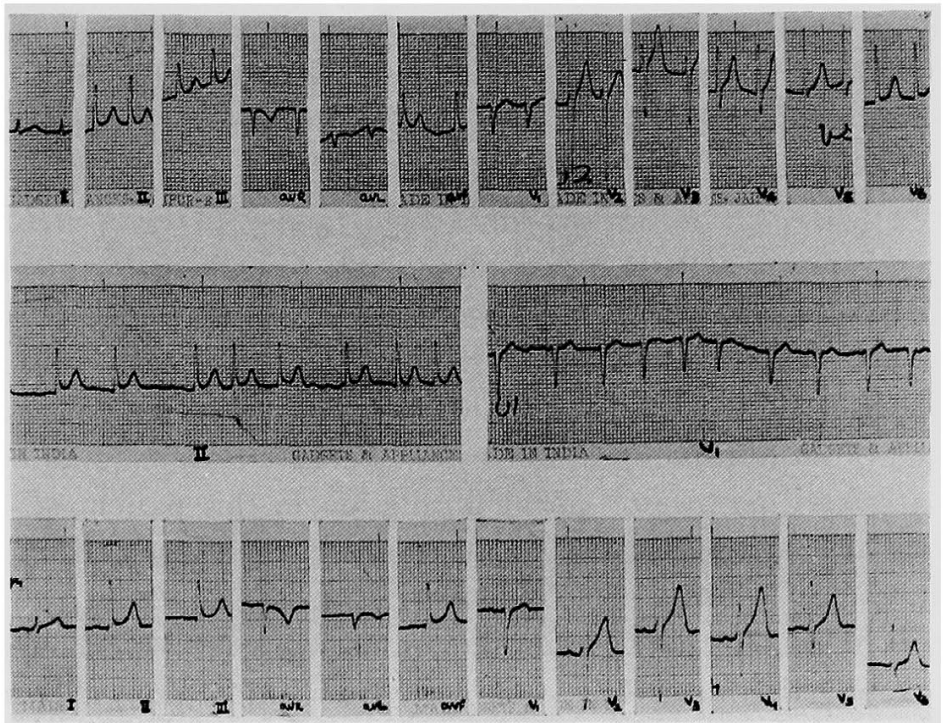

Fig. 2. Electrocardiogram of the second patient showing atrial fibrillation with a ventricular rate of $110 / \mathrm{min}$ in a 12 lead ECG (upper trace) and in rhythm strips leads II and $V_{I}$ (middle trace). Lower trace shows normal sinus rhythm after spontaneous reversion.

\section{Discussion}

Electrical injuries may occur due to contact with live wires or natural lightening. A number of cardiovascular effects of such an injury have been reported. These include myocardial infarction, transicnt accelerated hypertension, left ventricular dysfunction, cardiac rupture and rhythm disturbances. ${ }^{1-3)}$ The arrhythmias commonly encountered include premature ventricular contractions, ventricular and atrial tachycardia, ventricular fibrillation, bundle branch and complete heart blocks. ${ }^{31}$

Atrial fibrillation following an electrical shock is very uncommon. Butler and Gant in a study of 182 cases of electrical injury seen over a 20-year period, observed atrial fibrillation in only 2 cases, one of which required cardioversion. ${ }^{2)}$ Solem et al in a study of 64 cases with electrical injury also observed only 2 cases with atrial fibrillation. ${ }^{3)}$ In both these studies the electrical injury was due to high tension current in most cases. In the first study $2 / 3$ of patients had sustained high-voltage injuries and in the second $3 / 4$ of the cases had high-energy injuries. The electrical voltage causing injury resulting in atrial fibrillation is not given in these studies. Both our patients developed atrial fibrillation following exposure to household current of 220 volts. Fatal ventricular fibrillation has been described with an even lower 
voltage of 110 volts. ${ }^{2)}$ It is believed that low-voltage electrical current preferentially courses along neurovascular bundles ${ }^{3}$ and is therefore more dangerous to cardiac rhythm. It is therefore likely that such rhythm disturbances may occur more commonly than is generally believed.

Our first case was particularly interesting in view of the underlying WPW syndrome. Patients with WPW syndrome are known to have a high incidence of atrial fibrillation. In Wellens' series of 212 patients with WPW syndrome and tachyarrhythmias, $64 \%$ had only reciprocating tachycardia, $20 \%$ had atrial fibrillation alone and $16 \%$ had both. ${ }^{5}$ Electrical injury precipitated atrial fibrillation in our case. Because of very rapid conduction over the accessory pathway, ${ }^{61}$ atrial fibrillation in this patient resulted in a fast ventricular response causing hemodynamic compromise and required cardioversion.

In conclusion, electrical injury on contact with 220 volt, household current can cause atrial fibrillation. Its early recognition, especially in patients with fast ventricular response, can help in the rapid initiation of definitive therapeutic measures.

\section{REFERENCES}

1. Divincenti FG, Moncrief JA, Pruitt BA Jr: Electrical injuries: a review of 65 cases. J Trauma 9: 497, 1969

2. Butler ED, Gant TD: Electrical injuries, with special reference to the upper extremities. A review of 182 cases. Am J Surg 134: 95, 1977

3. Solem L, Fischer RP, Strate RG: The natural history of electric injury. J Trauma 17: 487,1977

4. Lewin RF, Arditti A, Sclarovsky S: Non invasive evaluation of electrical cardiac injury. Br Heart J 49: 190, 1983

5. Wellens HJJ: Wolf-Parkinson-White syndrome. Part 1. Diagnosis, arrhythmias, and identification of the high risk patients. Mod Concepts Cardiovasc Dis 52: 53, 1983

6. Boincau JP, Moore EN: Evidence for propagation of activation across an accessory atrioventricular connection in types A \& B pre-excitation. Circulation 41: 375, 1970 